\title{
StrategiesApplied forRenewable Energy Source Adoption in Indigenous Communities of La Guajira, Colombia
}

\author{
Edgar OjedaCamargo ${ }^{1}$, Helman Hernández Riaño ${ }^{2}$, Leonardo Bedoya Valencia ${ }^{3}$, \\ Agustín Barrios Sarmiento ${ }^{4}$, John Candelo Becerra ${ }^{5}$ \\ ${ }^{1}$ Facultad de Ingeniería, Universidad de la Guajira, Km 5 vía Maicao, Riohacha - Colombia. \\ E-mail:eojeda@uniguajira.edu.co \\ ${ }^{2}$ Departamento de Ingeniería Industrial, Universidad de Córdoba, Carrera 6 \# 76 -103, Montería - Colombia. \\ E-mail: hhernandez@correo.unicordoba.edu.co \\ ${ }^{3}$ Department of Engineering, Colorado State University - Pueblo,2200 Bonforte Blvd, \\ Pueblo, Colorado 81001- 4901 USA. \\ E-mail: l.bedoyavalencia@colostate-pueblo.edu \\ ${ }^{4}$ Departamento de Matemáticas y Estadística. Universidad del Norte, \\ Km 5 vía Puerto Colombia, Barranquilla - Colombia. \\ E-mail:abarrios@uninorte.edu.co \\ ${ }^{5}$ Departamento de Energía Eléctrica y Automática, Universidad Nacional de Colombia, \\ Sede Medellín, Cra. 80 No 65 - 223, Medellín, Colombia. \\ E-mail: jecandelob@unal.edu.co
}

\begin{abstract}
This study presents the results of the evaluation of some strategies to promote adoption of technologies that enable the use of renewable energy sources (RES) in Wayuu indigenous communities located in La Guajira, Colombia. We used an agent-based model representing the collective decision process within the communities, where three different types of agents are used to represent the members of the communities and their influence on the process of decision making. This process involves several discussions and meetings, using text to speech, lectures and training, and visits to other projects as strategies. Subsequently, using the model, a factorial experiment was conducted to compare the impact of various proposed and implemented strategies. The impact of the study measured the number of members willing to adopt new technologies in the community. In this sense, the best results with respect to the dissemination and adoption of RES in the communities under study were obtained by combining the strategies of text to speech and training lectures.
\end{abstract}

Keywords-Agent-Based Simulation, Wayuu, Renewable Energy, Diffusion Strategies, Indigenous Communities.

\section{INTRODUCTION}

The Department of La Guajira is located in northern Colombia and has geographical and climatic conditions that present a great challenge for the population, particularly for the people living in rural areas. This does not exclude the Wayuu communities that live today in very difficult conditions, affecting their living standards and their expectations of survival as a culture[1]. The Wayuu are an Amerindian group of the Arawak linguistic family [1] who live in household complexes called ranches, which are formed by a group of family dwellings.

This town is governed by a matrilineal kinship system, and its main economic activities are small livestock and trade [2]. The Department of La Guajira has problems with utility infrastructure, and this is worse in the villages, where road systems, telecommunications, electric power and water and sewage systems are inefficient or non-existent[2]. The case of the communities located in the Upper Guajira is one such example, where one of the main problems is the lack of electrical service due to the dispersed settlement pattern of these communities, making the investment in electrical networks not financially viable.

As an alternative solution to this problem, the use of RES in these communities, such as wind energy, solar photovoltaic, solar thermal, biomass, hydropower and so on, has been proposed by academics and some sectors of the regional government[3]. Given the geographic and climatic conditions, the alternative generation methods with more technical viability would be wind, solar photovoltaic and solar thermal, but the final selection will result from further studies. The social and cultural aspects of the Wayuu are very particular, so the process of adopting technologies for the use of RES is something that should be studied to ensure the success and sustainability of energy projects for these communities. Therefore, in this study, an agent-based simulation model is used to evaluate strategies that encourage the adoption of RES technologies in such communities. Agent-based simulation is a computational tool to represent social systems, as studied in this research, and to analysetheir behaviour[4]. The agent concepton which this tool is based is "a self-content program that can 
control its own actions, based on their perceptions of the environment"[5].The main properties of agent-based simulationare set out below [5]:

- They are autonomous (can operate without direct human control or other agents).

- They are interactive (with social skills, interacting with their environment and/or other agents) and have local knowledge (they receive only part of their immediate environment).

- With subjective perception, they have limited rationality.

- They are reactive (they perceive their environment and respond accordingly) and proactive (they can take the initiative based on objective behaviour).

- In addition, theyhave the potential to be programmed to have adaptation, learning, sophisticated planning and language (computer).

Literature shows various diffusion models, such as those presented in[6], where a model that determinedthe probability of purchasing a new article at time $\mathrm{T}$ was related to the number of previous buyers. In recent years, some authors have used it in the study of diffusion of energy innovations, as presented in [7]. The author suggestedan agent-based simulation model, which integrates a single-choice behaviour, and impact from the social network to which the person belongs, finding that this last can performan important task in diffusion acceleration.

In[8],the authorsdeveloped an agent-based model that simulates the diffusion process of alternative fuels on the market. This model consideredeconomic and social aspects in the decision process and feedback mechanisms. Its main conclusion was that the adoption of fuel differences is mainly due to the price, but other factors play an important role if the prices are similar. Similarly, in [9], the authorspresented an agent-based simulation model aimed at identifying possible government interventions to improve the diffusion of heating household technology based on wood pellets. They concluded that financial support and operational reliability should be applied simultaneously to accomplish a successful diffusion of the studied technology.

In[10], the researchersproposed an agent-based simulation model for the diffuse study of a new heating and micro-cogeneration technology regarding current alternatives. Within the household's decision-making process, the authors included economical, technological and social aspects, which allowed the suggested model to properly describe the studied reality.This study concluded that the commercial diffusion of new technology is significantly affected by fuel, natural gas and electrical energy prices, which must be considered when designing incentive policies. In [11], the authors exposed a hybrid agent-based simulation model, which allows one to evaluate the incentive and regulation effectiveness that promote photovoltaic solar energy systemdiffusion. The developed model integrates system dynamics with agent-based simulation to promote a more realistic simulated environment.

In addition to the documents found in literature related to energy innovation diffusion, different types of innovation studies have been conducted, such as environmental innovations[12], which proposed a simulation model of technology diffusion for domestic water saving; new products[13]-[17];and computer science innovations [18],[19]. However, asearch showed a lack of studies related to the diffusion of renewable energy sources in indigenous communities. In many countries, the zones where indigenous communities reside have great energy potential for electricity generation, making it necessary to conduct studies such as the one described in the present article, which allow us to understand the phenomena and contribute to the development of this type of energy sources.

\section{Methodology}

\section{A. Sample}

In the organizational characterization of the indigenous population living in the Upper Guajira, we considered a total of 1603 households in the Uribía indigenous communities, according to the population[20]. Then, we applied the probabilistic sampling method, given that all the elements (households) have the same possibility for being selected in the sample, where the probability of each population subject starts from $50 \%$.

The sample was calculated using (1), where $n$ is the sample; $N$ is the total population, equal to 1603 households located in the Upper Guajira; $z$ is the trust level, equal to $90 \%$, corresponding to 1.65 standard deviations; $p$ is the expected proportion, $50 \%$, equal to 0.5 for being chosen or not. $q=1-P,(1-0.5=0.5)$, and $e$ is the error, equal to $10 \%$. With the values shown, we obtained a sample of 65 households.

$$
n=\frac{z^{2} * p * q * N}{e^{2}(N-1)+z^{2} * p * q}
$$

Fig. 1 showsthe Upper Guajiraarea and the route at the zone where the study was conducted.This route was considered because it is in the zone where most of the Wayuu populationlives in the Upper Guajira. 


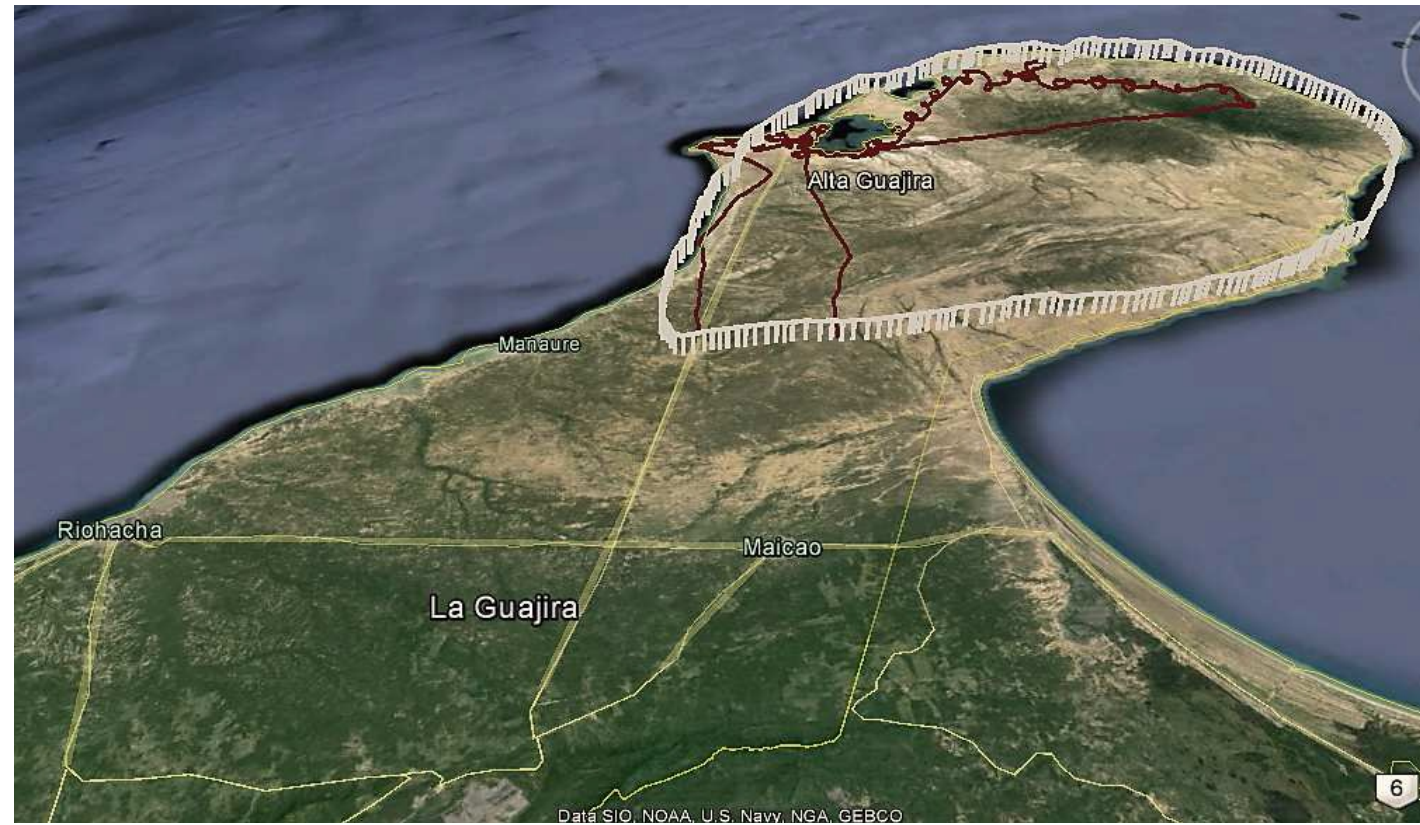

Fig. 1. Upper Guajira areas and the route at the zone of the highest Wayuu population. Source: Adapted from Google Earth ${ }^{\circledR}$

\section{B. Model Description}

Fig. 2 shows the collective decision process of the agents that may participate in the decision process of communities in the Upper Guajira. The agents included in this model are traditional authorities (red), advisors (blue), leader convinced of the virtues oftechnology (green) and the general population (yellow). In the model, all the agents that form the respective ranches are presented, including meeting places, generally an outdoor salon without walls and with palm leaf ceilings (identified in the model bya white square in the centre).

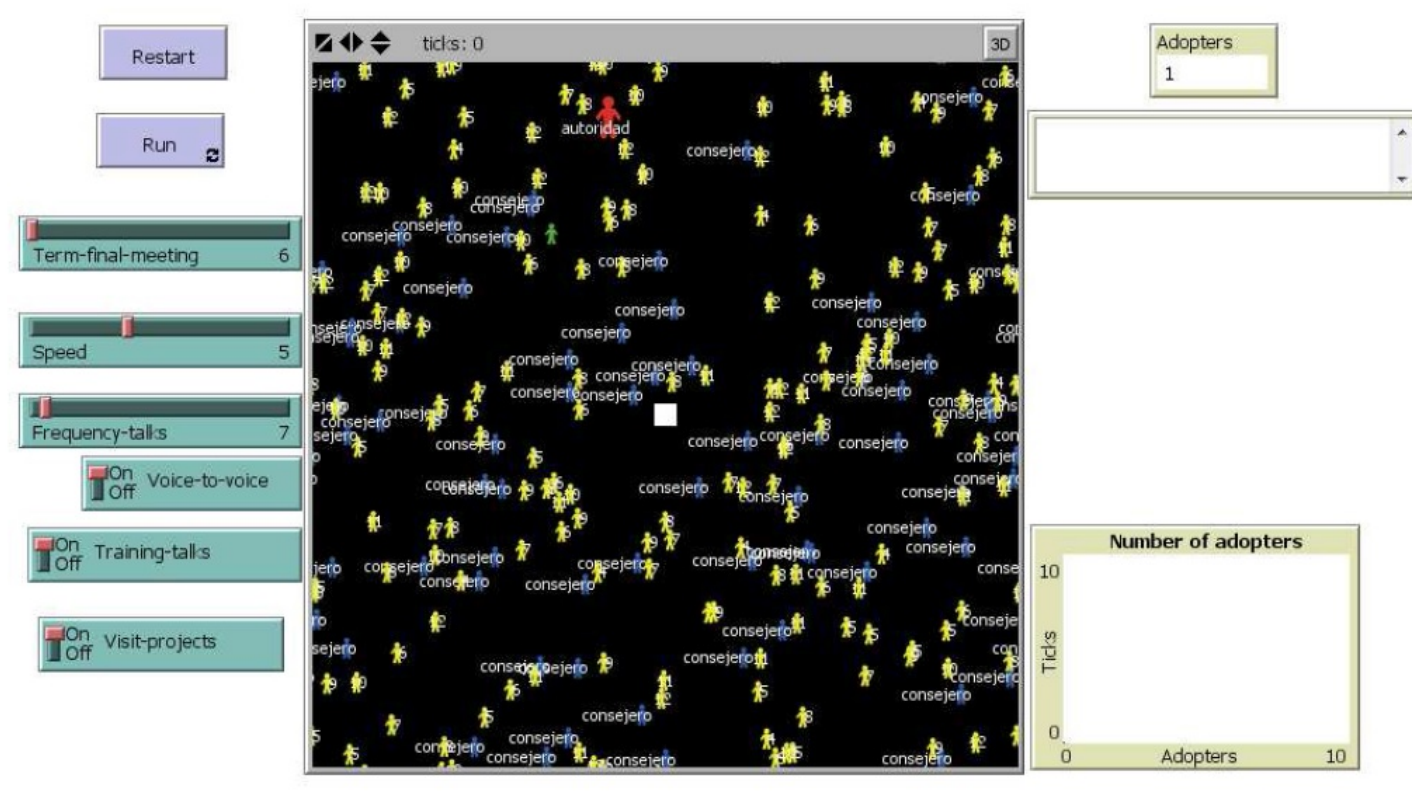

Fig. 2. Agent-based simulation model.

\section{Agent Decision Rules}

An important aspect of the model is that it represents the communication process between the members of the ranches in general terms, considering important cultural aspects such as traditional roots, family membership and territorial entrenchment. These elements determine the decision and instruction rules that govern agent behaviour and predominantly mark the Wayuu collective responses[2]. This causes new community members to adopt the elders' principles and knowledge. 


\section{Parameters and Initial Model Conditions}

All members of the communities meettheir normalrolesand in the model have theirrespective colour identifications. Then, westart to establish the initial conditions of the modelparameters, defining a deadline of 14days to setthe final meeting with all members of the respective communities for the decision-making process. We also considered a speed parameter equal to five and a discussion-developing frequency of seven days. Finally, the three selected strategiesare active to accomplish the technology diffusionpenetration that facilitates the use of RES.

\section{E. Decision-making Process}

The decision-making process is different for each community. However, we considered a general process to apply this methodology to start achieving a decision-makingprocess for each community. Fig. 3 shows the general steps the communities follow to make the decision. Where TA is the traditional authority, CS is the counsellors, $\mathrm{CM}$ is the community members, $\mathrm{CL}$ represents the community leaders, $\mathrm{AD}$ is the advisors, and PM is the project members.

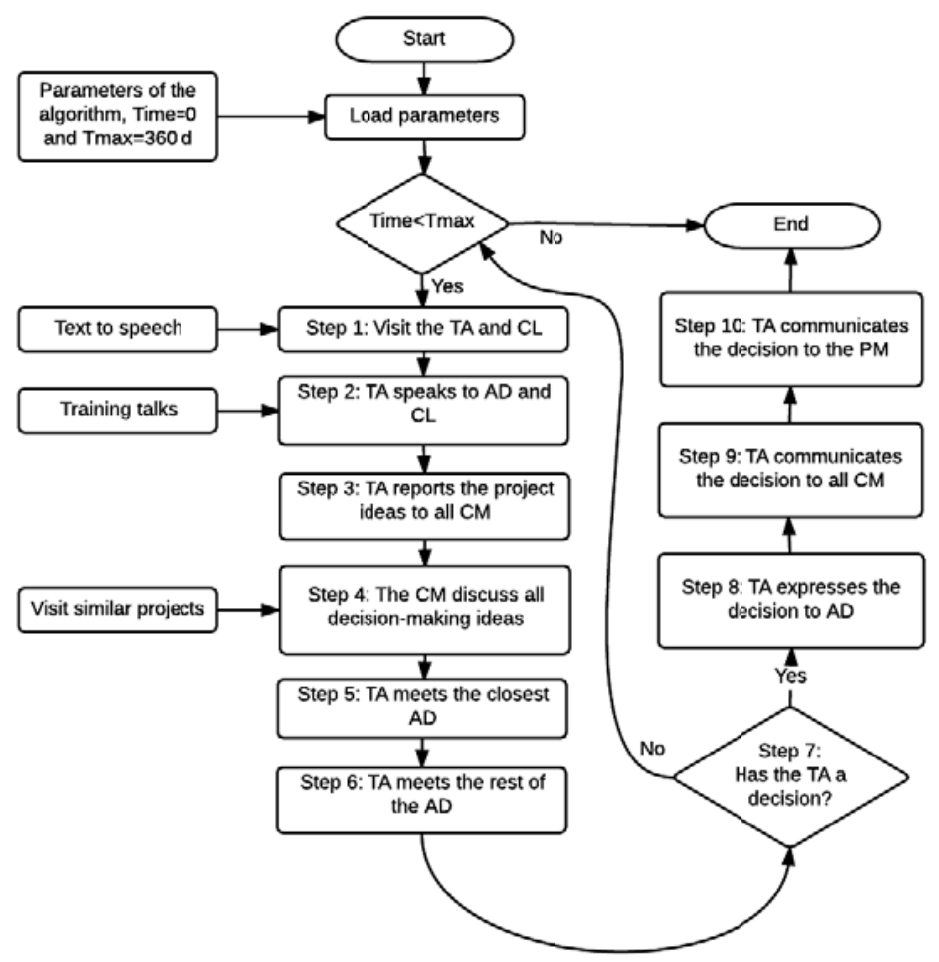

Fig. 3. Steps of the methodology applied to the study.

The important steps of this methodology are:

- Step 0. Start.

- Step 1. We visit the TA and the CL to explain the project idea. They listen, and at the end (a leader is convinced, adopting the green colour), the TA convokes a first meeting with the $\mathrm{AD}$ and other $\mathrm{CL}$ to analyse the project idea before discussing it with all the respective CM.

- Step 2. During the first meeting, the TA speaks with the AD and the CL. Then, they convoke a second meeting for the CM to listen to the project idea.

- Step 3. During the second meeting, an assembly is conducted where the TA invites all CM to listen to the project idea.

- Step 4. During a third meeting, the CM discuss all decision-making ideas.

- Step 5. During a fourth meeting, the TA meets with the closest AD, including the leaders, to conduct a pros and cons project analysis.

- Step 6. During a fifth meeting, the TA meets with the rest of the AD. (These are the ones not so close to the TA.)

- Step 7. The TA makes a decision. 
- Step 8. During a sixth meeting, the TA expresses all the decision to all the AD.

- Step 9. In the seventh meeting, the TA tells all CM the decision in general assembly.

- Step 10. The TA invites all the PM to meet and tells them the decision.

- Step 11. End.

\section{F. Technology-adopting Provision Strategies}

We selected three strategies: text to speech (TS), lectures and training (LT) and visitsto other projects by the indigenous population (VP). Inthe text-to-speech case, we proposed to convince acommunity member (preferably an advisor), allowinghim/her to persuade the rest of the community toadopt the technology. In this strategy, it is assumedthat the advisor plays the role of opinion leaderin the community. Regarding the lectures and trainingstrategy for the indigenous population, these will be conductedfrequently by the experts in topics relatedto RES. Likewise, the visits to other projectswill allow the indigenous people to learn about the experiences of similarimplemented projects in other communities. For the evaluationof the suggested strategies to promote RES adoption, an agent-basedsimulation model was designed using NetLogo [21]. We asked some experts on population culture, a master in indigenous languages involved in training and research of Wayuu ethnicity and a member of each community to verify the model considered in this research.Similarly, the suggested model was presented toseveral leaders of each community, who hold the title of 'pütche'ejachi'(orators) and are experts in resolving conflicts.

\section{G. Sensitivity Analysis}

A sensitivity analysis can be conducted considering various strategiesand decision variables.For example, if the TS and LT strategies are disabled from the model, anagreement is not achieved among all the members of thecommunity (i.e., not all become green). Likewise, if these two strategies are enabled and theVP strategy is disabled, the community is convinced, a result that we failto obtain if the term is reduced from 14 to 6days between the start of the process and the final meeting.

This last section of the analysisallows us to conclude that a week is enoughtime to achieve all community members'agreementthrough the LT and TSstrategies. Furthermore, a model to conduct a factorialexperiment was also used in[22],allowing the authors to evaluate the suggested strategies' performancebased on the number of adopting members.The experiment analysis was developed through avariance analysis, whose results are shown in the followingsection.

\section{III.RESULTS AND ANALYSIS}

Table I shows the variance analysis according to the strategy implemented to adopt technologies in the studied indigenous population. This table shows that the P-values of all strategies and their combinations are less than 0.05 , which indicates they have relevant statistical effects over the adopting population obtained in the simulation.

TABLE I. Variance Analysis for Adopting Population

\begin{tabular}{|c|c|c|c|c|c|}
\hline $\begin{array}{c}\text { Source of } \\
\text { Variation }\end{array}$ & $\begin{array}{c}\text { Sum of } \\
\text { Squares }\end{array}$ & $\begin{array}{c}\text { Degrees } \\
\text { of Freedom }\end{array}$ & $\begin{array}{c}\text { Mean } \\
\text { Square }\end{array}$ & F-value & P-value \\
\hline TS & 36195.1 & 1 & 36195.1 & 2573.87 & 0.0000 \\
\hline TL & 59902.6 & 1 & 59902.6 & 4259.74 & 0.0000 \\
\hline VP & 3630.06 & 1 & 3630.06 & 258.14 & 0.0000 \\
\hline TS and TL & 30189.1 & 1 & 30189.1 & 2146.78 & 0.0000 \\
\hline TS and VP & 517.563 & 1 & 517.563 & 36.8 & 0.0003 \\
\hline TL and VP & 495.063 & 1 & 495.063 & 35.2 & 0.0003 \\
\hline TS, TL and VP & 232.563 & 1 & 232.563 & 16.54 & 0.0036 \\
\hline Total error & 112.5 & 8 & 14.0625 & & \\
\hline Total (corrected) & 131274 & 15 & & & \\
\hline
\end{tabular}

For development of the experiment, the lowerlevel $(-1.0)$ of each of the strategies was consideredthe absence of the strategy, and the higher level (1.0) wasconsidered an intense implementation of thecorresponding strategy.Regarding the case-by-case evaluated strategies, Fig. 4 shows the training lecture effectiveness,achieving a mean of 150 adopting members in largeWayuu communities with 151 or more members. 


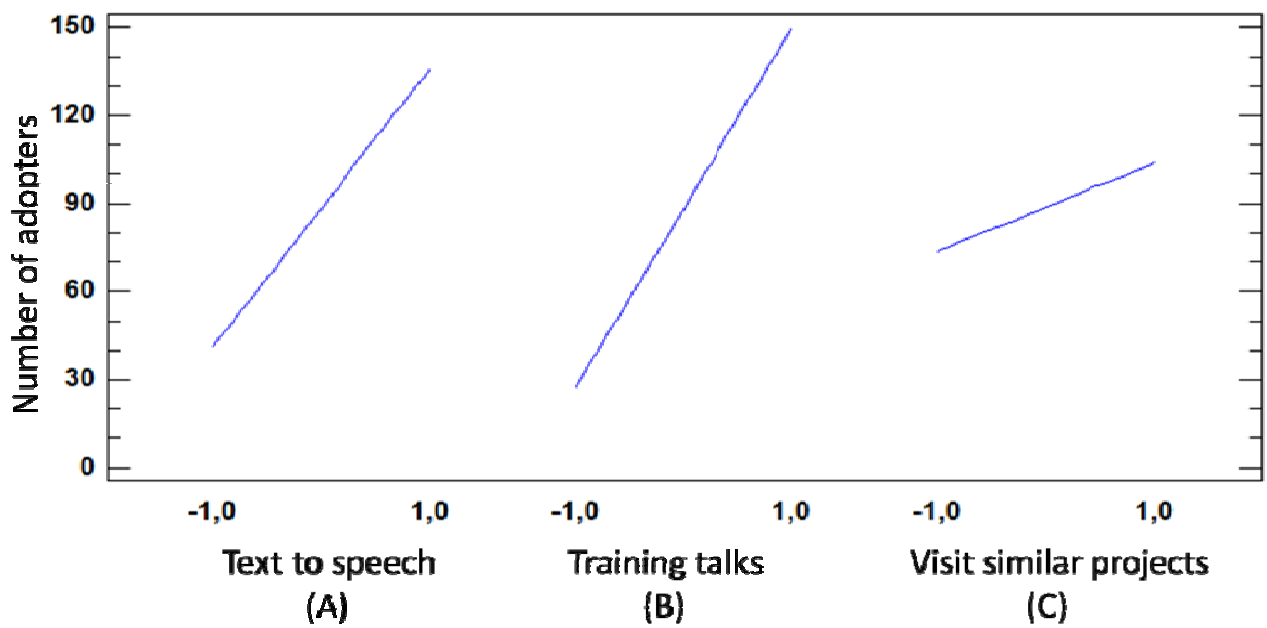

Fig. 4. Indigenous people adopting RES technologies according to the use of a single strategy.

Given that all the discussionstrategy combinationshave relevant statistical effects, the text-to-speech andtraining lectures stand out in this test, achieving themost effectiveness and managing a mean of 241 adoptingmembers, as shown in Fig. 5, where AB indicatesthe TS and TL strategies, AC is the TS and VP strategies and BC is the TL and VP strategies.

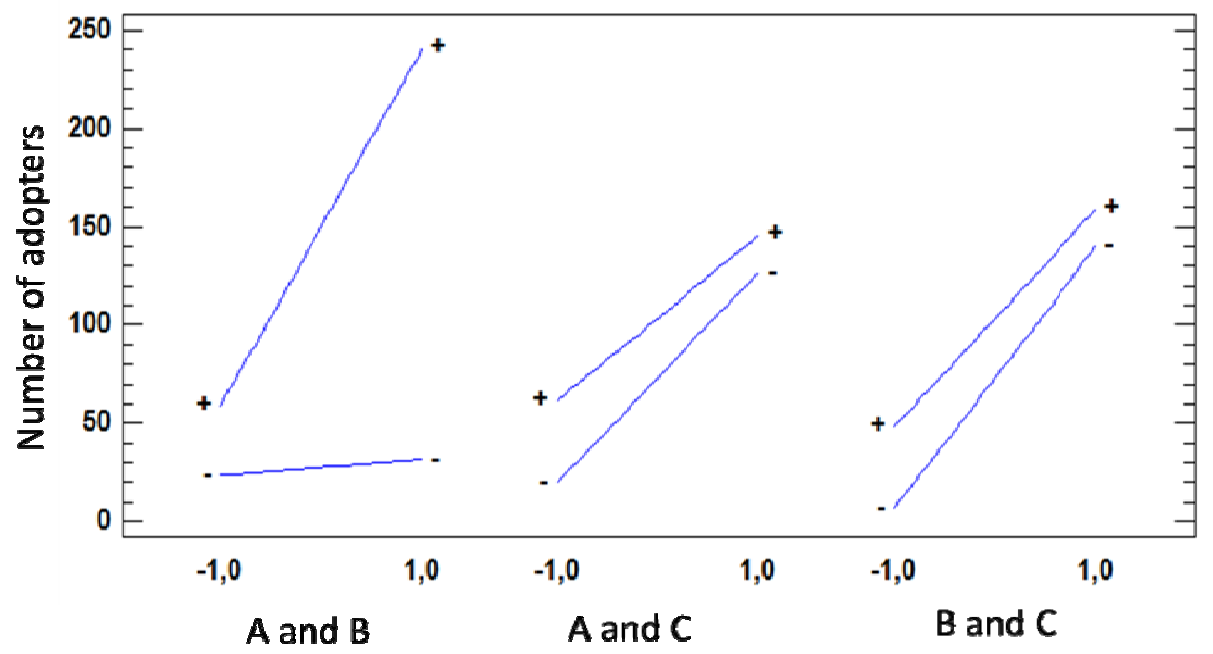

Fig. 5. Indigenous people adopting RES technologies according to combinations of strategies.

Table IIshows the most effective strategies in renewable energy diffusionafter studying some Wayuu communities. It is worth emphasising the variance analysis assumptions: normality, homoscedasticity and independence of the residuals were verified.

TABLE III. Most Effective Strategies for Adopting RES Technologies

\begin{tabular}{|l|c|}
\hline \multicolumn{1}{|c|}{ Strategy } & Adopting Mean \\
\hline Text to speech & 136.375 \\
\hline Text to speech and visits & 145.75 \\
\hline Lectures & 150 \\
\hline Lectures and visits & 159.5 \\
\hline Text to speech and lectures & 254 \\
\hline
\end{tabular}




\section{IV.CONCLUSION}

This paper presented the results of the evaluation of some strategies to promote the adoption of renewable energy technologies in the Wayuu indigenous communities located in the Department of La Guajira, Colombia. The studyshowed that lecture training andtext-to-speech strategies to promote the adoption of RES obtained the best results,with adopting means of 150 and 136, respectively.Furthermore, the combination of thetext-to-speech and lecture training strategiesachieved a mean of 241 adopting members, which represented better results for the promotion of RES technologies in this indigenous population. This finding could beobtainedbecausethe Wayuu are a group with a dominant verbal tradition,and oral communication is fast and effective in these communities. Theaforementioned implies that to improve the achievedresults, using combined strategiesbased on verbal communication is recommended.Finally,it is important to point out that this research didnot consider aspects such as promotion strategy cost, communication between communitiesor other relations between the Wayuu population and the rest ofthe indigenous organisation in the country.

\section{REFERENCES}

[1] N. Leal González, J. Alarcón Puentes, and M. Leal Jérez, "Relaciones de poder y nuevos liderazgos en el pueblo Wayuu," Bol. Antrpológico, vol. 21, pp. 187-208, 2003.

[2] C. Puerta Silva, "El proyecto del Cerrejón: un espacio relacional para los indígenas wayuu , la empresa minera y el Estado colombiano,” Boletín Antropol. Univ. Antioquia, vol. 24, no. 41, pp. 149-179, 2010.

[3] R. Bolívar, J. Mostany, and M. del C. García, “Petróleo Versus Energías Alternas: Dilema Futuro,” Interciencia, vol. 31, pp. 10-12, 2006.

[4] C. Sansores and J. Pavón, “Simulación Social Basada en Agentes,” Intel. Artif. Rev. Iberoam. Intel. Artif., vol. 9, pp. 71-78, 2005.

[5] M. Arroyo Menéndez and S. Hassan Collado, "Simulación de procesos sociales basada en agentes software," Empiria. Rev. Metodol. Ciencias Soc., no. 14, p. 139, Oct. 2007.

[6] F. M. Bass, “A New Product Growth for Model Consumer Durables,” Manage. Sci., vol. 15, no. 5, pp. 215-227, Jan. 1969.

[7] M. Tran, "Agent-behaviour and network influence on energy innovation diffusion," Commun. Nonlinear Sci. Numer. Simul., vol. 17, no. 9, pp. 3682-3695, Sep. 2012.

[8] O. van Vliet, B. de Vries, A. Faaij, W. Turkenburg, and W. Jager, "Multi-agent simulation of adoption of alternative fuels," Transp. Res. Part D Transp. Environ., vol. 15, no. 6, pp. 326-342, Aug. 2010.

[9] B. Maya Sopha, C. A. Klöckner, and E. G. Hertwich, "Exploring policy options for a transition to sustainable heating system diffusion using an agent-based simulation,” Energy Policy, vol. 39, no. 5, pp. 2722-2729, May 2011.

[10] A. Faber, M. Valente, and P. Janssen, "Exploring domestic micro-cogeneration in the Netherlands: An agent-based demand model for technology diffusion,” Energy Policy, vol. 38, no. 6, pp. 2763-2775, Jun. 2010.

[11] J. Zhao, E. Mazhari, N. Celik, and Y.-J. Son, "Hybrid agent-based simulation for policy evaluation of solar power generation systems,” Simul. Model. Pract. Theory, vol. 19, no. 10, pp. 2189-2205, Nov. 2011.

[12] N. Schwarz and A. Ernst, "Agent-based modeling of the diffusion of environmental innovations - An empirical approach," Technol. Forecast. Soc. Change, vol. 76, no. 4, pp. 497-511, May 2009.

[13] M. Amini, T. Wakolbinger, M. Racer, and M. G. Nejad, "Alternative supply chain production-sales policies for new product diffusion: An agent-based modeling and simulation approach,” Eur. J. Oper. Res., vol. 216, no. 2, pp. 301-311, Jan. 2012.

[14] M. E. Schramm, K. J. Trainor, M. Shanker, and M. Y. Hu, "An agent-based diffusion model with consumer and brand agents," Decis. Support Syst., vol. 50, no. 1, pp. 234-242, Dec. 2010.

[15] L. Kuandykov and M. Sokolov, "Impact of social neighborhood on diffusion of innovation S-curve," Decis. Support Syst., vol. 48, no. 4, pp. 531-535, Mar. 2010.

[16] S. A. Delre, W. Jager, T. H. A. Bijmolt, and M. A. Janssen, "Targeting and timing promotional activities: An agent-based model for the takeoff of new products,” J. Bus. Res., vol. 60, no. 8, pp. 826-835, Aug. 2007.

[17] S. Kim, K. Lee, J. K. Cho, and C. O. Kim, "Agent-based diffusion model for an automobile market with fuzzy TOPSIS-based product adoption process,” Expert Syst. Appl., vol. 38, no. 6, pp. 7270-7276, Jun. 2011.

[18] M. A. Zaffar, R. L. Kumar, and K. Zhao, "Diffusion dynamics of open source software: An agent-based computational economics (ACE) approach,” Decis. Support Syst., vol. 51, no. 3, pp. 597-608, Jun. 2011.

[19] P. Twomey and R. Cadman, "Agent - based modelling of customer behaviour in the telecoms and media markets," info, vol. 4, no. 1, pp. 56 - 63, Feb. 2002.

[20] DANE, Proyecciones nacionales y departamentales de población 2005-2020. Bogotá D.C., 2009.

[21] J. C. Thiele and V. Grimm, "NetLogo meets R: Linking agent-based models with a toolbox for their analysis," Environ. Model. Softw., vol. 25, no. 8, pp. 972-974, Aug. 2010.

[22] D. C. Montgomery, Diseño y Análisis de experimentos, LIMUSA WIL. Arizona, Estados Unidos. 